\title{
Recurrent reciprocal deletions and duplications of 16p13.11: the deletion is a risk factor for MR/MCA while the duplication may be a rare benign variant
}

\author{
F D Hannes, ${ }^{1}$ A J Sharp, ${ }^{2}$ H C Mefford, ${ }^{2}$ T de Ravel, ${ }^{1}$ C A Ruivenkamp, ${ }^{3}$ M H Breuning, ${ }^{3}$ \\ J-P Fryns, ${ }^{1} \mathrm{~K}$ Devriendt, ${ }^{1} \mathrm{G}$ Van Buggenhout, ${ }^{1}$ A Vogels, ${ }^{1} \mathrm{H}$ Stewart, ${ }^{4} \mathrm{R}$ C Hennekam, \\ G M Cooper, ${ }^{2}$ R Regan, ${ }^{6}$ S J L Knight, ${ }^{6}$ E E Eichler, ${ }^{7}$ J R Vermeesch ${ }^{1}$
}

- Supplementary data are published online only at http:// jmg.bmj.com/content/vol46/ issue4

For numbered affiliations see end of article

Correspondence to: Dr J R Vermeesch, Center for Human Genetics, Herestraat 49, 3000 Leuven, Belgium; joris. vermeesch@uz.kuleuven.ac.be

The first two authors contributed equally to this work

Received 5 October 2007 Revised 28 December 2007 Accepted 7 January 2008 Accepted for Online First 7 January 2008

\section{ABSTRACT}

Background: Genomic disorders are often caused by non-allelic homologous recombination between segmental duplications. Chromosome 16 is especially rich in a chromosome-specific low copy repeat, termed LCR16.

Methods and Results: A bacterial artificial chromosome (BAC) array comparative genome hybridisation (CGH) screen of 1027 patients with mental retardation and/or multiple congenital anomalies (MR/MCA) was performed. The BAC array CGH screen identified five patients with deletions and five with apparently reciprocal duplications of $16 p 13$ covering $1.65 \mathrm{Mb}$, including 15 RefSeq genes. In addition, three atypical rearrangements overlapping or flanking this region were found. Fine mapping by highresolution oligonucleotide arrays suggests that these deletions and duplications result from non-allelic homologous recombination (NAHR) between distinct LCR16 subunits with $>99 \%$ sequence identity. Deletions and duplications were either de novo or inherited from unaffected parents. To determine whether these imbalances are associated with the MR/MCA phenotype or whether they might be benign variants, a population of 2014 normal controls was screened. The absence of deletions in the control population showed that 16p13.11 deletions are significantly associated with MR/MCA $(p=0.0048)$. Despite phenotypic variability, common features were identified: three patients with deletions presented with MR, microcephaly and epilepsy (two of these had also short stature), and two other deletion carriers ascertained prenatally presented with cleft lip and midline defects. In contrast to its previous association with autism, the duplication seems to be a common variant in the population $(5 / 1682,0.29 \%)$.

Conclusion: These findings indicate that deletions inherited from clinically normal parents are likely to be causal for the patients' phenotype whereas the role of duplications (de novo or inherited) in the phenotype remains uncertain. This difference in knowledge regarding the clinical relevance of the deletion and the duplication causes a paradigm shift in (cyto)genetic counselling

Non-allelic homologous recombination (NAHR) between neighbouring intrachromosomal segmental duplications (also termed low copy repeats, or LCRs) is the main mechanism underlying genomic disorders. Several recurrent clinical syndromes are caused by either gains or losses of sequences flanked by segmental duplications. Since the initial discovery that Charcot-Marie-Tooth disease and HNPP (hereditary neuropathy with liability to pressure palsies) are caused by the duplication and the reciprocal deletion at $17 \mathrm{p} 11.2$, respectively, many other recurrent clinical syndromes have been shown to be caused by NAHR. ${ }^{1}$ The finding that around $4 \%$ of the human genome is made up of intrachromosomal segmental duplicons led to speculation that many more unrecognised recurrent rearrangement syndromes might exist. ${ }^{2}$ The advent of array comparative genome hybridisation $(\mathrm{CGH})$ has enabled genome-wide screening for copy number variations (CNVs) in large patient populations leading to the identification of several novel low copy repeat-mediated rearrangements. ${ }^{3} 4$

Chromosome 16 is especially rich in intrachromosomal segmental duplications. During recent primate evolution, chromosome 16 has undergone intense segmental duplication activity, and $>10 \%$ of the euchromatic region of the $p$ arm is composed of highly complex low copy repeats. ${ }^{56}$ During evolution, these blocks were generated in a stepwise fashion, generating multiple subunits termed LCR16a-t, with a size range of $20-600 \mathrm{~kb}$ and sharing $>97 \%$ sequence similarity. ${ }^{7}$ The complex architecture of chromosome 16p therefore suggests it as an excellent candidate region for novel microdeletion syndromes. ${ }^{3}$ Recently, Ballif et $a l^{8}$ reported a novel microdeletion syndrome of 16p11.2-p12.2, which seems to be mediated by NAHR between 16p segmental duplicons. In addition to this novel syndrome, various studies analysing $\mathrm{CNV}$ s in patients with mental retardation and/or multiple congenital anomalies (MR/MCA) have reported imbalances of $16 \mathrm{p} 13 . .^{9-11}$ However, the relevance of these findings remains unclear.

During the screening of 1027 patients with MCA and/or MR, we identified 6 deletions and 7 duplications of 16p12-p13, apparently caused by NAHR between LCR16. Our detailed analyses of these imbalances define $16 \mathrm{p} 13.11$ as a region of recurrent microdeletion/duplication and suggest that the deletion is a risk factor for MR/MCA but the clinical relevance of the duplication is uncertain.

\section{METHODS}

\section{Selection of patients}

This study involved patients with MR/MCA, ascertained from three sources: (1) those diagnosed by the clinical geneticist of Leuven, Belgium $(\mathrm{n}=500)$, (2) children and young adults from a variety of UK clinical genetics centres, community learning disability teams and other sources,
This paper is freely availat online under the BMJ Journa unlocked scheme, see http:// jmg.bmj.com/info/unlocked.dtl 
including hospital neuropaediatricians $(n=372),{ }^{3}$ and (3) DNA from autopsies of fetuses with $\geqslant 1$ congenital anomalies at Children's Hospital and Regional Medical Center (Seattle, WA) after death or elective termination $(\mathrm{n}=155) .{ }^{12}$ All were reported to have a normal karyotype at $550 \mathrm{G}$-band resolution, and in many cases cryptic subtelomeric rearrangements and other specific genetic abnormalities had been excluded.

\section{Array comparative genome hybridisation}

Patients were analysed using two different bacterial artificial chromosome (BAC) array CGH platforms. Patient samples from Leuven, Belgium $(n=500)$ were hybridised to a custom BAC array with clones spaced at approximately $1 \mathrm{Mb}$ intervals throughout the genome, according to the protocol of Menten et al. ${ }^{13}$ Regions were scored as CNVs if one clone passed the threshold of $4 \times$ the normal standard deviation (SD), and if $\geqslant 2$ flanking clones passed the threshold of $\log _{2}(3 / 2)-2 \times \mathrm{SD} .{ }^{14}$ Patient samples from the UK $(n=372)$ and USA $(n=155)$ were hybridised to a custom BAC array consisting of $\sim 2000$ clones targeted to regions of the genome flanked by segmental duplications. ${ }^{10}$ Regions were scored as $\mathrm{CNV}$ if the $\log _{2}$ ratio of $\geqslant 2$ consecutive clones each exceeded $2 \times \mathrm{SD}$ of the autosomal clones in dye-swap replicate experiments. ${ }^{3}$

An additional patient with a $16 \mathrm{p} 13.11$ duplication was identified by array CGH to human $105 \mathrm{~K}$ genome-wide oligonucleotide arrays (Agilent Technologies, Diegem, Belgium) according to the manufacturer's instructions. In brief, genomic DNAs from the patient and from a single sex-matched reference patient were separately double-digested using the restriction endonucleases AluI and RsaI (Promega, Leiden, The Netherlands) and purified using Microcon centrifugal filter devices (Millipore Corporation, Missouri, Minneapolis, USA). Then $1.5 \mu \mathrm{g}$ of the digested products were differentially labelled by random priming with Cy3-dUTP and Cy5-dUTP (Perkin Elmer, Foster City, California, USA) and cohybridised to the array for $48 \mathrm{hrs}$ at $65^{\circ} \mathrm{C}$ in a rotating oven. Parental DNAs were also hybridised using this method. The hybridised arrays were washed and scanned (Microarray Scanner; Agilent). Image data were extracted using Feature Extraction V.8.5 software (Agilent) and the data analysed using CGH Analytics V.3.4 software (z-score method setting) (Agilent).

To refine thebreakpoints of these rearrangements, we utilised oligonucleotide arrays. One oligoarray consisting of 385000 isothermal custom made probes (length 45-75 bp) covering a number of chromosomal regions, including this $5 \mathrm{Mb}$ region of chromosome 16p (mean density, 1 probe per $131 \mathrm{bp}$ ) (NimbleGen Systems, Madison, Wisconsin, USA). Hybridisations were performed as described previously, ${ }^{15}$ and samples from a single normal man were used as the reference (GM15724; Coriell, Camden, New Jersey, USA).

The second oligoarray used (GeneChip Human Mapping 262K NspI; Affymetrix, Santa Clara, California, USA) contains 26226425 oligonucleotides. In this experimenrt, 250 ng genomic DNA was processed according to the manufacturer's instructions (Affymetrix GeneChip Human Mapping 500K Manual; http://www.affymetrix.com). Copy number was assessed using DNA-Chip Analyzer (dChip) software 2006. ${ }^{16}$ Regions of copy number gain and loss were found using the hidden Markov model output of dChip.

\section{Real-time quantitative PCR}

Real-time quantitative PCR (qPCR) was performed as previously described ${ }^{13}$ with minor modifications. Primers were designed from RepeatMasked sequence (www.repeatmasker. org/) using Primerexpress V.2.0.0 oligo design software (Applied Biosystems, Lennik, Belgium), and validated with in silico PCR and genome searching using Blat software (http://genome.ucsc. edu/). Single-nucleotide polymorphisms (SNPs) were excluded from the primer sequence (SNP track in UCSC Browser). Realtime qPCR was performed using a commercial preparation (Q-PCR MasterMix Plus for SYBR Green I without UNG (uracil- $N$-glycosylase); Eurogentec, Liege, Belgium) according to the manufacturer's instructions. Each reaction was performed in duplicate in a final volume of $15 \mu \mathrm{l}$ containing $6-30 \mathrm{ng} / \mu \mathrm{l}$ genomic DNA, $1.25 \mu \mathrm{M}$ forward/reverse primer, and $7.5 \mu \mathrm{l}$ SYBR Green mastermix.

\section{Control populations}

The first control population comprised 722 unrelated individuals from Belgium who had been referred for clinical genetic testing for haemochromatosis or cystic fibrosis. Genomic DNA of each individual was extracted from blood lymphocytes according to standard procedures, and assayed by real-time qPCR using primer pair 3 (Eurogentec, Seraing, Belgium) for detection of copy number changes of $16 \mathrm{p} 13.1$. Thresholds were set at a fold difference of 0.8 and 1.3. All samples surpassing these thresholds were analysed twice to confirm the presence of copy number changes.

A second control population, comprising 960 unrelated Caucasian adults (age 40-70 years) from the USA, were genotyped using a chip array (HumanHap300 Genotyping BeadChips; Illumina, San Diego, California), comprising 〜317 000 HapMap SNPs distributed throughout the genome. Each individual was enrolled in the Pharmacogenomics and Risk of Cardiovascular Disease (PARC) study, which aims to identify genetic contributors to the variable efficacy of statin drugs on cardiovascular disease risk (http://www.pharmgkb.org/do/ serve?objId=5\&objCIs=Project). Hybridisations, data analysis and copy number analysis, focused on this region of $16 p$, were performed according to published protocols. ${ }^{17}$

\section{CASE REPORTS}

\section{Patients carrying 1.65 Mb 16p13.11 deletions}

Patient 1 (ID 224725)

This adult patient is the only affected member of five siblings. She has severe MR, therapy-resistant epilepsy and behavioural problems. She has short stature $(143 \mathrm{~cm}$, less than third percentile (P3) of $155 \mathrm{~cm}$ ) and microcephaly (occipitofrontal circumference $(\mathrm{OFC}) 51 \mathrm{~cm}$; P3 $=52.2 \mathrm{~cm}$ ). She has a short nose, smooth philtrum, wide mouth and fine palpebral fissures. She has difficulty in expressive language and has an ataxic gait.

\section{Patient 2 (ID 335606)}

This adult proband and his brother were referred with severe $M R$. The proband has short stature $(150 \mathrm{~cm}$; P3 $=168 \mathrm{~cm})$, microcephaly (OFC $51 \mathrm{~cm}$; P3 $=52.2 \mathrm{~cm}$ ), pectus excavatum and limb spasticity. He is being treated for epilepsy.

\section{Patient 3 (ID 22698)}

This adult man with moderate $M R$ is the only child of nonconsanguineous parents. His stature and $\mathrm{OFC}$ are normal and he is obese (103 kg; >P97). He is not dysmorphic, is extremely talkative, and displays intermittent verbal aggression and self-mutilation. 


\section{Patient 4 (ID 224358)}

This patient is the male sibling of a dizygotic twin pregnancy that occurred via in vitro fertilisation with intracytoplasmic sperm injection (ICSI). At 16 weeks gestation, ultrasound examination demonstrated abnormalities in the female fetus. The pregnancy went to term. The male fetus has a ventricular septal defect (VSD) and a right-sided aorta. He is subject to frequent infections because of his low CD3 count - he has a $22 \mathrm{q} 11$ deletion. The $1856 \mathrm{~g}$ cyclopic female fetus had a crown rump length of $28.5 \mathrm{~cm}$ and a head circumference of $26 \mathrm{~cm}$ (proportionally microcephalic). Holoprosencephaly, agenesis of the nose, a midline upper lip notch and a median cleft palate were present together with two pre-auricular tags on the left, and a right dysplastic ear with a pre-auricular tag and an atretic auditory canal.

\section{Patient 5 (ID FA-180)}

Prenatal ultrasound at 18 weeks gestation showed a cleft lip on the right, a possible intracranial abnormality with dilated lateral ventricles, and thinning of the cortical mantle. The pregnancy was terminated at 21 weeks. Autopsy showed posthaemorrhagic hydrocephalus with marked ventriculomegaly, cortical thinning, a hypoplastic falx cerebri, cleft lip on the right side, two preauricular skin tags on the right, and cleft T1 and T3 vertebral bodies. Physical growth parameters were consistent with gestational age. This patient was reported by Mefford et al. ${ }^{12}$

\section{Patients carrying 1.65 Mb 16p13.11 duplications Patient 6 (ID 325275)}

The second child of non-consanguineous parents, this patient was born after an uneventful pregnancy. He has moderate MR. He was constipated from birth and at 6 months was diagnosed with Hirschsprung disease, for which he had a resection and an end-to-end anastomosis. Behavioural problems developed at 5 years of age and he has received special education. As an adult, he has normal biometry, bushy eyebrows and a mandibular overbite.

\section{Patient 7 (ID IMR277)}

This patient was originally reported by Kriek et $a l^{9}$ as part of a multiplex ligation-dependent probe amplification (MLPA) screen of 105 patients selected for developmental delay and/or congenital malformations. He had learning problems in primary school, but is not clearly dysmorphic and has no serious behavioural problems. The extent of the duplication was verified using array CGH and fluorescent in situ hybridisation. MLPA and real-time qPCR of the parents confirmed the de novo nature and the size of this duplication.

\section{Patient 8 (ID IMR277)}

This patient has severe learning disabilities with limited use of language, poor vocabulary and repetitive speech. She displays challenging, agitated behaviour marked by shouting, handclapping, kicking, hitting and throwing objects at people, although this has improved with age. She has epilepsy.

\section{Patient 9 (ID IMR220)}

The patient is the only child of non-consanguineous parents. He walked at 13 months, and later was described as clumsy but not dyspraxic. Speech has always been problematic. His delay was moderate (IO of 55), and he had behavioural problems such as increased impulsivity and limited attention control. Grommets were inserted for upper airway infections, but otherwise there were no major physical problems. At $14 \frac{3 / 4}{4}$ years of age, OFC was $54.7 \mathrm{~cm}$ (50th centile). He was noted to have large simple ears, thick lips, a large tongue, and large and somewhat puffy hands with small nails. CT scan of the brain was normal. Metabolic screening of urine showed no abnormalities. EEG was normal. Ophthalmological examination showed bilateral astigmatism. Fragile X syndrome (FRAXA) testing showed a full expansion in the patient and a premutation in his mother, which had been inherited from her father.

\section{Patient 10 (ID 0xP078)}

An ultrasonography examination at 20 weeks gestation revealed microcephaly in this patient. This was confirmed after delivery and at 4 years of age the $\mathrm{OFC}$ was $44 \mathrm{~cm}(\mathrm{P} 3=48.6 \mathrm{~cm})$. The patient had brachycephaly, telecanthus, abnormal eyebrows, deep-set eyes, epicanthic folds, a pinched nasal tip, prominent nose and small jaw. She also had a VSD, an umbilical hernia, deep creases on the palms and soles, and clinodactyly. An MRI scan showed a small brain with delayed myelination and prominent extra axial fluid-filled spaces. The patient has delayed speech and hyperactive behaviour with aggressive episodes. At 6 years of age, she attends normal school with a large amount of learning support. The child's mother also has a small head, mild learning difficulties and poor temper control. Her mother (the proband's maternal grandmother) has a small head and mild learning difficulties. One developmentally and behaviourally normal maternal aunt carries the duplication and one aunt with mild learning difficulties and aggressive behavioural is cytogenetically normal.

\section{Patients carrying larger atypical $16 p 13.11$ rearrangements Patient 11 (ID 66529)}

The only child of non-consanguineous parents, this patient was born at term with a birth weight of $3200 \mathrm{~g}$. She had feeding and respiratory difficulties in the neonatal period. As an adult, she has an asymmetrical face with left facial nerve paresis, a short neck with reduced mobility, bilateral epicanthal folds, strabismus, choroid colobomata, and previously had atresia of the right choana. An atrial septal defect type 2 closed spontaneously and she has a unique right kidney with double ureters. She has hearing difficulties, and a CT scan showed aplasia of the semicircular canals and abnormal middle ear bones. Her behaviour is normal. CHD7 mutation analysis was normal.

\section{Patient 12 (ID IMR184)}

This patient was reported in Sharp et al. ${ }^{3}$

Patient 13 (ID 20754)

This sixth child, born to a mother with pre-eclampsia, weighed $1800 \mathrm{~g}$ at full term. She had neonatal seizures and marked developmental delay, not walking and talking until 4 years of age. As an adult, she has has short stature $(150 \mathrm{~cm}$; $\mathrm{P} 3=155 \mathrm{~cm}$ ) and microcephaly (OFC $50.5 \mathrm{~cm}$; P3 $=52.2 \mathrm{~cm}$ ). She has an IQ of 38 and has cyclic depression.

\section{RESULTS}

\section{Recurrent microdeletion/duplication of 16p13.11}

Array CGH was performed on 1027 patients or fetuses with unexplained MR/MCA using one of two custom BAC arrays. ${ }^{10}{ }^{13}$ In total, 13 patients with $16 \mathrm{p} 12-\mathrm{p} 13$ rearrangements were found (1.3\%), 6 of whom carried a deletion and 7 a duplication. Ten of these rearrangements (five deletions and five 
Figure 1 Molecular overview of recurrent deletions and reciprocal duplications in patients 1-10.

(A) ENSEMBL overview (freeze: 24-042007) which visualises $1 \mathrm{Mb}$ bacterial artificial chromosome (BAC) clones, the genes involved in the imbalance, the copy number variable regions ${ }^{19}$ and chromosome bands. (B) The location of real-time quantitative PCR primers used to fine-map the breakpoints, are depicted. (C) The extent of the deletion and duplication is shown by red and green bars, respectively in typical del/dup patients. (D) Organisation of the segmental duplication structure at the distal and proximal breakpoints of recurrent 16p13.1 rearrangements. Each coloured bar represents a pairwise alignment with $>98 \%$ identity.

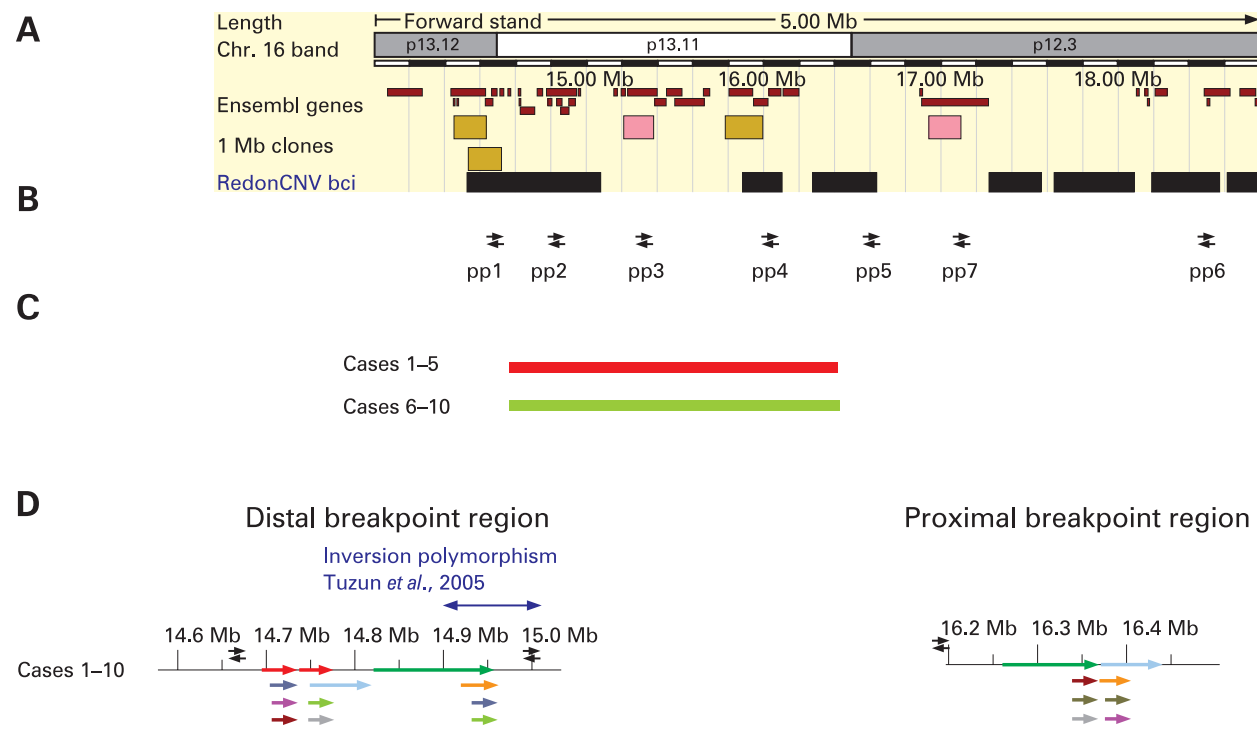

duplications, patients 1-10) seemed to involve the same $\sim 1.65 \mathrm{Mb}$ region of $16 \mathrm{p} 13.11$, suggesting that they probably represent the reciprocal events of NAHR (fig 1). Three additional patients carried atypical larger rearrangements. These were up to $3.4 \mathrm{Mb}$ in size, and either overlapped or flanked the more common 1.65 Mb 16p13.11 deletions/duplications seen in the other 10 patients. Real-time qPCR was used to confirm the results of the array CGH analysis, and clearly distinguished patients with deletions and duplications from normal controls (fig 2). For one patient with a typical deletion (patient 4), testing of parental DNA showed that the microdeletion was inherited from the phenotypically normal father. In contrast, for one patient with a typical duplication (patient 10), testing revealed three generations in which the duplication initially seemed to segregate with a mild or more severely abnormal phenotype, but testing of additional family members showed that the duplication and phenotype did not cosegregate.

\section{Rearrangement breakpoints localise to LCR16 segmental duplication blocks containing a positively selected gene family} Each rearrangement was mapped at higher resolution using either 262k NspI SNP arrays (Affymetrix) (fig 3) or a custom oligonucleotide array (Roche Nimblegen, Madison, Wisconsin, USA) (fig 4). These data confirmed the results of the BAC array $\mathrm{CGH}$, and localised the breakpoints of each rearrangement to segmental duplications composed of large clusters of LCR16. ${ }^{7}$ Significantly, patients $1-10$ had both proximal and distal breakpoints that localised to the same intervals (distal breakpoints, 14.7-14.75 Mb, proximal breakpoints 16.3-16.77 Mb). These duplication blocks, which define the common breakpoint regions, were also found to be strongly polymorphic in copy number in normal controls (fig. 4, supplementary material online). These polymorphic breakpoint regions correspond to LCR16a/LCR16b motifs, which have been shown to have undergone rapid proliferation during primate evolution and contain a gene family, Morpheus, which has a signature of extreme positive selection. ${ }^{18}$ Real-time qPCR using primers flanking these segmental duplications confirmed that that the breakpoints occurred within these LCRs (fig 2).

There are 15 RefSeq genes in the common $1.65 \mathrm{Mb}$ recurrent rearrangement region. Given that microcephaly and brain malformations are the major recurrent characteristic in our patients with deletions, NDE1 was believed to be a good candidate for a dosage-sensitive gene that might underlie the features of these deletions. In order to test the hypothesis that the deletion acts by unmasking the presence of a recessive mutation on the remaining allele, we sequenced the NDE1 gene in four of our patients with deletions (1-4). Primers covering all eight exons and the $5^{\prime}$ and $3^{\prime}$ untranslated regions (suppplementary table 1 online) were used for direct sequencing of genomic DNA, but no mutations were found.

\section{The microdeletion associates with the MR/MCA phenotype}

Although neither 16p13.11 duplications or deletions have been found in 210 unrelated HapMap individuals, ${ }^{19}$ nor in 122 other individuals sampled from the normal population, ${ }^{10} 2021$ a larger and population matched sample size was needed in order to draw a statistically meaningful conclusion as to their pathogenic significance. Therefore, the copy number of the commonly rearranged $16 \mathrm{p} 13.1$ region in 722 population matched controls ascertained from the Belgian population, and in a further 960 Caucasian controls drawn from the USA, were evaluated. These analyses did not detect any deletions of this region in the 1682 controls tested, but did reveal the presence of five $16 \mathrm{p} 13.11$ duplications. Although we do not have access to detailed clinical information for these five controls, the method used to ascertain them suggests that they are unlikely to have significant developmental abnormalities, but we cannot exclude possibility that they might have abnormal learning, memory or behavioural characteristics. Combining these data with previously published analysis of 332 controls results in a total control population of 2014, including 5 carriers of $16 \mathrm{p} 13.1$ duplications, but no carriers of deletions. This compares with 5 deletions and 7 duplications ascertained from 1027 patients with MR/MCA. We therefore conclude that deletions of $16 \mathrm{p} 13.1$ are significantly associated with patient phenotype ( $p=0.0048$, Pearson $\chi^{2}$ test with simulated $p$ value, based on 10000 replicas), but show incomplete penetrance, as demonstrated by their presence in some apparently unaffected relatives. The incidence of duplications in association with disease is not significantly different from that in controls ( $p=0.1273$, Pearson's $\chi^{2}$ test). This observation leads us to a number of possible conclusions regarding the duplication including that it might (1) be truly clinically benign, (2) be 

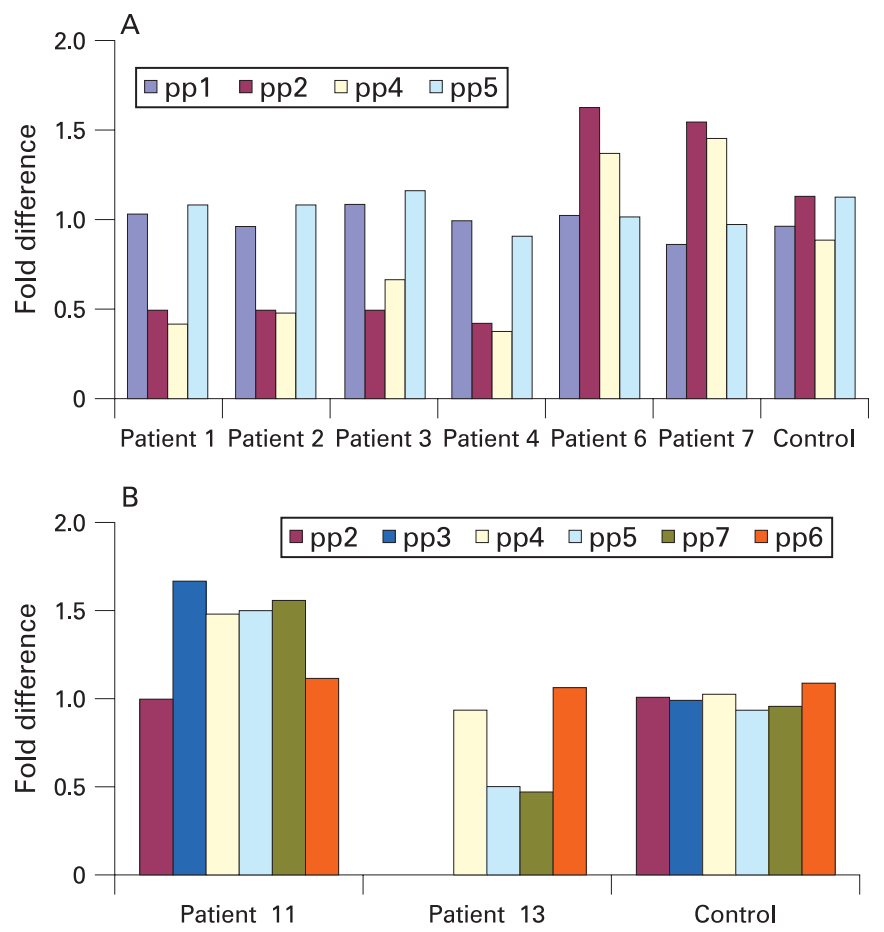

Figure 2 Real-time quantitative PCR results with different primer sets flanking the breakpoint regions. (A) In all individuals carrying the common deletion/duplication (patients 1-10), the distal breakpoints occur between primers pp1 and pp2, and the proximal breakpoint is defined by primers pp4 and pp5. (B) The extent of the atypical duplication and deletion identified in patients 11 and 13 were delineated by primersets $\mathrm{pp} 2 / \mathrm{pp} 3$ and $\mathrm{pp} 4 / \mathrm{pp} 5$, respectively, for distal breakpoints and between pp6 and pp7 for the proximal breakpoint. The presence of two copies for a locus was defined by a fold difference of 1 whereas a fold difference of 0.5 or 1.5 corresponds to a deletion or a duplication, respectively.

compatible with a phenotype that has passed unnoticed (or has not been excluded) in the control population tested or (3) work in combination with other predisposing factors to give an $M R$ phenotype.

\section{Atypical rearrangements of chromosome 16p12-p13}

In addition to the common recurrent $1.65 \mathrm{Mb}$ microdeletion/ duplication of $16 \mathrm{p} 13.11$ observed in 10 patients, 3 atypical rearrangements were found. Two patients (11 and 12) carried a larger duplication of $\sim 3.4 \mathrm{Mb}$ in size, overlapping the typical duplication. The distal breakpoint of these atypical duplications was located between 15.0-15.4 Mb and the proximal breakpoint was located within a third LCR16 cluster (18.3-18.4 Mb). Results of real-time qPCR with primer pair 2 (supplementary table 2 online) were normal whereas the results using primer pair 3 showed the presence of a duplication (fig 2). This result confirms that the duplication starts in a more proximal LCR16 than the typical duplication. This duplicated region includes 12 RefSeq genes. The normal mother of patient 11 was found to be a carrier of this same duplication.

One further patient (patient 13) carried a 1.6-2.1 Mb deletion that flanked the common rearrangement region. This atypical deletion had its distal breakpoint in the second cluster and its proximal breakpoint in the third LCR16 cluster. The region includes 2 RefSeq genes. This imbalance was inherited from a phenotypically normal mother. A summary of all 13 rearrangements found is shown in table 1.

\section{DISCUSSION}

We describe five patients carrying identical $1.65 \mathrm{Mb}$ deletions of 16 13.11 encompassing 15 genes. In addition, we found five patients carrying apparently reciprocal duplications of this same region. The rearrangement breakpoints are located in low copy repeats implying that non-allelic homologous recombination between these flanking LCRs mediates these rearrangements. Three further patients presenting with larger atypical rearrangements showed breakpoints that also mapped to clusters of LCR16.

Despite careful parental analysis, observations of rearrangements of $16 \mathrm{p} 13.11$ make it difficult to distinguish between disease-causing events (generally presumed to be de novo) and benign variants (that do not contribute to a phenotype). Two deletions and one duplication were found to be inherited from an apparently normal parent, and another duplication was inherited from a clinically mildly abnormal parent. Conversely, we also found a duplication that occurred de novo. Previous studies have reported 16p13.11 deletions occurring both de novo and by inheritance from a normal parent, while duplications were reported to be inherited from normal parents in two families. ${ }^{11}{ }^{22}{ }^{23}$ One interpretation of these observations could be that rearrangements of this region are benign variants, and that the observed phenotypes are coincidental with the presence of the imbalance. However, one case-control study reported a significantly higher incidence of the del16p13.11 in patients with MR/MCA, implying that the del16p13.11 is a risk factor contributing to the MR/MCA phenotype. The duplication is present in equal frequency in the normal and the patient population, indicating this variant is compatible with a normal phenotype. The identification of this dup16p13.11 in a patient with fragile X (patient 9) in our study lends support to this hypothesis. Recently, Ullmann et a ${ }^{11}$ reported three carriers of dup16p13.11 in a cohort of 182 people with autism. Because the duplication was found in 5 out of 2014 normal participants in our study, the duplication seems overrepresented in the autistic population ( $p=0.023$, Fisher exact test). More studies are needed strengthen this association.

Three of the four adult patients with $16 \mathrm{p} 13.11$ deletions had both microcephaly and seizures, and the two fetuses with the deletions had brain anomalies, one of which also had relative microcephaly. The same three adult patients also have small stature. Small stature and dysmorphic features were also a feature of one of the patients described by Ullman et al. ${ }^{11}$ In contrast, our fourth adult patient and a previously described deletion carrier ${ }^{22}$ had normal head circumference $(55.3 \mathrm{~cm})$, while one previously reported patient had macrocephaly. ${ }^{11}$

Although the typical $16 \mathrm{p} 13.11$ duplication may be a benign variant, it is striking that four of our duplication carriers not only presented with MR but also behavioural problems. Similarly, members of two of three families with duplications reported by Ullman et a ${ }^{11}$ had similar behavioural problems. Although we do not have data on the behavioural phenotypes of all patients with MR/MCA tested using the arrays, the occurrence of this type of behaviour in this patient population seems higher than average, and hence, it seems plausible that dup16p13.11 carriers may have a predisposition for aggressive behaviour.

To date, most genomic imbalances have been classified as either benign or pathogenic and most microdeletion syndromes are presumed to be well-defined clinical conditions. However, even well-known genomic disorders can be phenotypically heterogeneous and more variable than originally thought, owing to incomplete penetrance or variable expression. The variability 


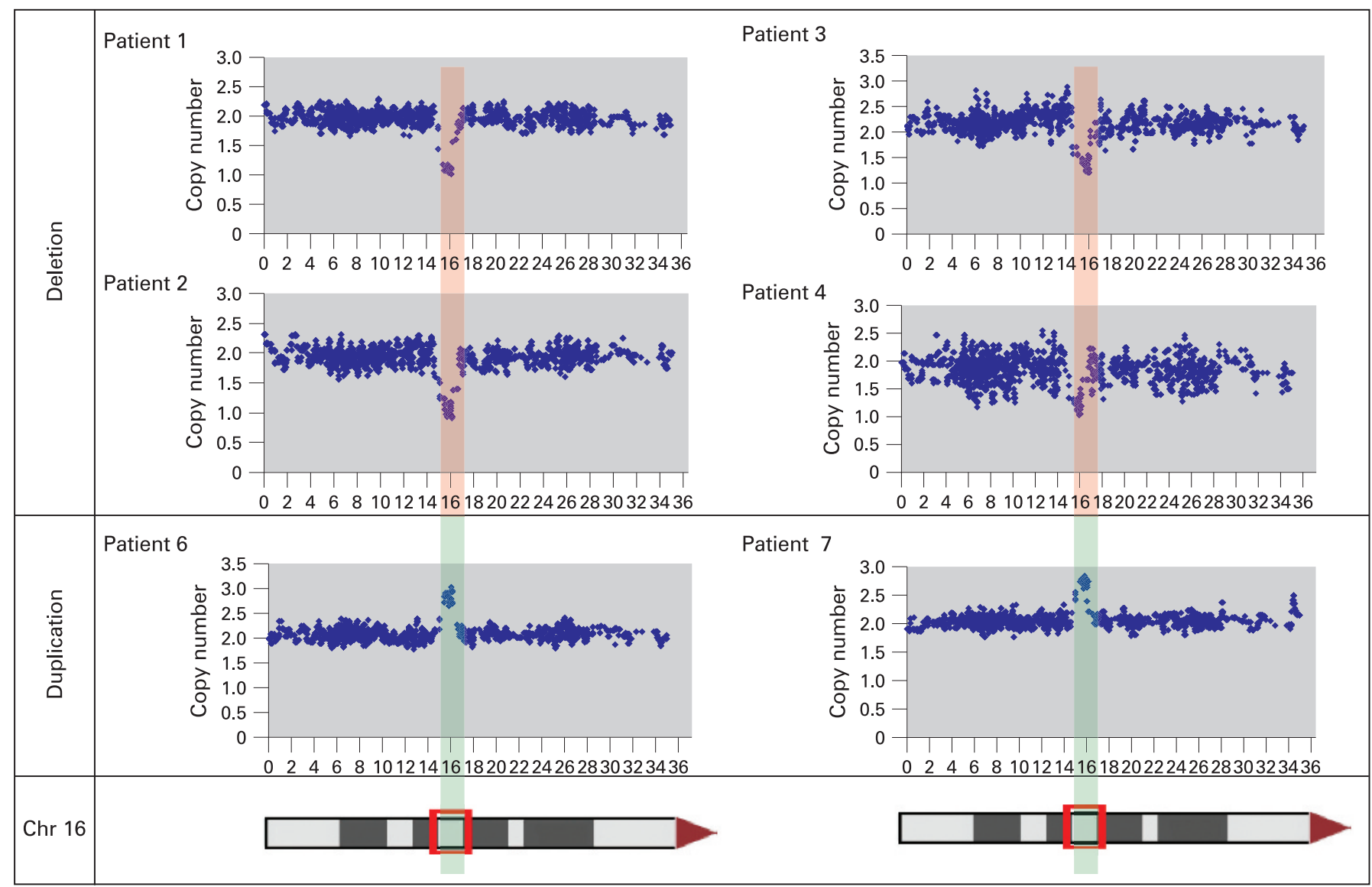

Figure 3 Detection of 16p12-p13 imbalances defined by the 262k Nsp/ SNP array. Data from the common $16 \mathrm{p} 13.111 .65 \mathrm{Mb}$ rearrangements are shown. Each plot has physical probe position on $16 p$ ( $x$-axis) against probe intensity ratio ( $y$-axis). Red shading, common deleted region; green shading, duplication in patients 1-4, 6 and 7 . Chr, chromosome.

of the del22q11 phenotype originally led to their different clinical classification as DiGeorge syndrome (heart and thymus defects) (OMIM 188400), Sprintzen syndrome (speech difficulties) or velocardiofacial syndrome (VCFS) (conotruncal anomaly face) (OMIM 192430). Recently, several reports have been published about atypical patients with 22q11 deletions. ${ }^{24} 25$ Equally, in dup22q11 carriers, the phenotype may range from severe MR through to completely unaffected, and various minor developmental anomalies are noted. ${ }^{26} 27$ In addition, 22q11 duplications can be inherited from apparently normal parents. $^{26}{ }^{28}$ Therefore, it is possible that $16 \mathrm{p} 13.11$ duplications might also be causative and the heterogeneous phenotype of our patients explained in part by (1) the unbiased selection criteria, (2) variability due to other genetic or possibly environmental determinants, (3) incomplete penetrance, (4) variable expression or (5) unmasking of recessive alleles. ${ }^{29}$ In particular, owing to the presence of del16p13.11 in a normal parent of one of our probands, we set out to test the latter hypothesis. Because microcephaly was observed in two of the three adult patients with typical deletions and in one of the two fetuses with deletion, NDE1 was considered an excellent candidate gene for this phenotype. NDE1 is strongly expressed in brain, ${ }^{30}$ and forms complexes with LIS1, a dosage-sensitive gene that is crucial for neuronal migration and cerebral development, and that is known to underlie Miller-Dieker lissencephaly syndrome (OMIM 247200). Furthermore, Nde1-null mice show microcephaly. ${ }^{31}$ However, sequencing of all exons of NDE1 in four patients with deletions did not reveal any mutation on the remaining allele, suggesting that this is not the mechanism responsible for the phenotype in our patients. Another plausible candidate gene is NTAN1 (asparagine-specific N-terminal amidase). Mouse models deficient for this enzyme showed alterations in activity, social behaviour and memory. ${ }^{32}$ However although this region is reported in the Redon database (http:// projects.tcag.ca/variation/) to have CNVs, learning and memory defects and aberrant social behaviour could not be excluded among controls and therefore the NTAN1 gene remains a good candidate gene.

Imprinting is a mechanism that could potentially explain the presence of these rearrangements in unaffected relatives. ${ }^{11}$ However, there are no known imprinted genes on chromosome 16 (http://www.geneimprint.com/site/genes-by-species). Furthermore, for both deletions and duplications of $16 p$ we observed the inheritance of these imbalances from normal parents through both the maternal and paternal germ lines, indicating that imprinting does not significantly influence patient phenotype of this disorder.

In addition to the common $1.65 \mathrm{Mb}$ rearrangement observed in the 10 patients reported here, 3 "atypical" chromosomal imbalances either overlapping or flanking this common region were found in patients with MR/MCA. Breakpoints for all three imbalances were also located within LCR16 sequences. However, the atypical $3.4 \mathrm{Mb}$ duplication seems to be mediated by different LCR16s compared with the atypical deletion. Therefore, the complex structure of the LCR16s in this region seems to be involved in generating a variety of different chromosomal 


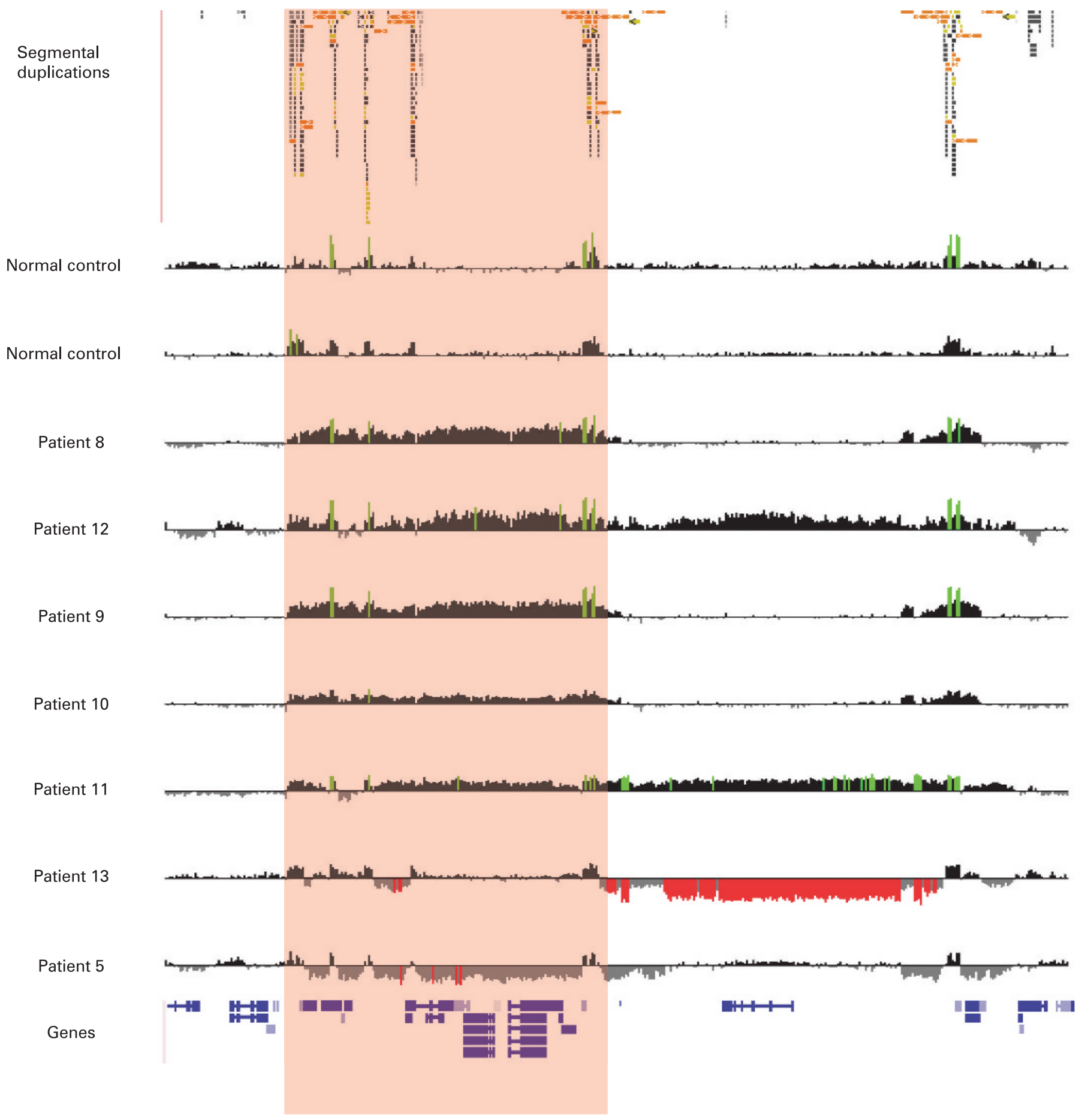

Figure 4 High-resolution oligonucleotide array mapping of seven 16p12.3-p13.11 rearrangements, of which four have a common distal breakpoint (14.7-14.75 Mb). For those four patients with the common 1.65 Mb rearrangement (red shading), the proximal breakpoints also map to a second LCR16 cluster (16.3-16.77 Mb). Another three patients have an atypical rearrangement: patients 11 and 12 show an atypical larger duplication, with the distal breakpoint between 15.0-15.4 Mb and the proximal breakpoint located within a third LCR16 cluster (18.3-18.4 Mb), and patient 13 has an atypical deletion with proximal breakpoint in the third LCR16 cluster and distal breakpoint in the second cluster. Data from normal control individuals show that there is marked copy number variation in the LCR16 clusters that define these three breakpoint regions. Note that the high degree of homology between these LCR16s also results in false-positive signals from probes that are identical to those within the true deletion/duplication in patients 5, 8 and 9. The image has a $5 \mathrm{Mb}$ region of 16p12-p13 (chr16:14 000 000-19 000000 ). For each individual, deviations of probe log ${ }_{2}$ ratios from zero are depicted by grey/black lines, with those exceeding a threshold of $1.5 \mathrm{SD}$ from the mean probe ratio shown in green and red to represent relative gains and losses, respectively. Segmental duplications of increasing similarity $(90-98 \%$, 98-99\%, and >99\%) are represented by grey/yellow/ orange bars, respectively.

rearrangements. The finding of variably sized rearrangements on chromosome $16 \mathrm{p}$ is similar to that observed for other recurrent genomic disorders, such as the Prader-Willi/Angelman syndrome, ${ }^{33}$ Smith-Magenis syndrome, ${ }^{34}$ and the $15 \mathrm{q} 24$ deletion syndrome, ${ }^{35}$ in which recombination within alternate LCRs can result in recurrent deletions and duplications of different sizes. 
Table 1 Genotype-phenotype correlation of patients with deletion or duplication of 16p12-p13

\begin{tabular}{|c|c|c|c|c|c|}
\hline Patient (Deciphercode) & Phenotype & Pattern of inheritance & $\begin{array}{l}\text { Type of } \\
\text { imbalance }\end{array}$ & $\begin{array}{l}\text { Distal } \\
\text { breakpoint (Mb) }\end{array}$ & $\begin{array}{l}\text { Proximal } \\
\text { breakpoint }(\mathrm{Mb})\end{array}$ \\
\hline 1 (CHG00002371) & $\begin{array}{l}\text { Severe } M R, 10=38 \text {, short stature }(143 \mathrm{~cm}) \text {, microcephaly }(51 \mathrm{~cm}) \text {, } \\
\text { epilepsy, ataxia }\end{array}$ & $\begin{array}{l}\text { Parents not available } \\
\text { for testing }\end{array}$ & Deletion & $14.7-14.75$ & $16.3-16.77$ \\
\hline 2 (CHG00002372) & $\begin{array}{l}\text { Severe MR, short stature }(150 \mathrm{~cm}) \text {, microcephaly }(51 \mathrm{~cm}) \text {, epilepsy, } \\
\text { pectus excavatum, limb spasticity }\end{array}$ & $\begin{array}{l}\text { Parents not available } \\
\text { for testing }\end{array}$ & & & \\
\hline 4 (CHG00001230) & $\begin{array}{l}\text { Term fetus; autopsy showed holoprosencephaly, nose agenesis, midline } \\
\text { upper lip notch, midline cleft palate, dysplastic external ear and atretic } \\
\text { auditory canal on right, preauricular skin tags bilaterally, relative } \\
\text { microcephaly }\end{array}$ & $\begin{array}{l}\text { Phenotypically normal } \\
\text { father carries deletion }\end{array}$ & & $14.7-14.75$ & $16.3-16.77$ \\
\hline 5 & $\begin{array}{l}\text { Fetus at } 21 \text { weeks; autopsy showed post-hemorrhagic hydrocephalus } \\
\text { with marked ventriculomegaly, cortical thinning, hypoplastic falx cerebri, } \\
\text { cleft lip on right, two preauricular skin tags on right, and cleft T1 and T3 } \\
\text { vertebral bodies. Physical growth parameters were consistent with } \\
\text { gestational age }\end{array}$ & $\begin{array}{l}\text { Parents not available } \\
\text { for testing }\end{array}$ & & $14.7-14.75$ & $16.3-16.77$ \\
\hline 7 (LEI)00002370) & $\begin{array}{l}\mathrm{MR} \text {, mild developmental delay, learning disabilities. Originally reported by } \\
\text { Kriek et al. }{ }^{9}\end{array}$ & de novo imbalance & \multirow{4}{*}{ Duplication } & $14.7-14.75$ & $16.3-16.77$ \\
\hline 8 & $\begin{array}{l}\text { Severe learning disabilities with limited use of language, poor vocabulary } \\
\text { and repetitive speech, epilepsy. Challenging, agitated behaviour marked } \\
\text { by shouting, hand-clapping, kicking, hitting and throwing objects at } \\
\text { people, although this has improved with age }\end{array}$ & $\begin{array}{l}\text { Phenotypically normal } \\
\text { father carries } \\
\text { duplication }\end{array}$ & & $14.7-14.75$ & $16.3-16.77$ \\
\hline 9 & $\begin{array}{l}\text { Moderate developmental delay, behavioural problems (increased } \\
\text { impulsivity, limited attention span). Large simple ears, thick lips, large } \\
\text { tongue, large puffy hands and small nails. Also has an expansion of the } \\
\text { FRAXA triplet repeat }\end{array}$ & $\begin{array}{l}\text { Parents not available } \\
\text { for testing }\end{array}$ & & $14.7-14.75$ & $16.3-16.77$ \\
\hline 10 & $\begin{array}{l}\text { Microcephaly found at } 20 \text { weeks gestation. At } 4 \text { years of age OFC } 44 \mathrm{~cm} \\
\text { (P3 = 48.6 cm). Brachycephaly, telecanthus, abnormal eyebrows, deep } \\
\text { set eyes, epicanthic folds, pinched nasal tip, prominent nose, small jaw, } \\
\text { VSD, umbilical hernia, deep palmar and plantar creases, speech delay, } \\
\text { hyperactive behavioural with aggressive episodes. Mother has small head } \\
\text { (no OFC) }\end{array}$ & $\begin{array}{l}\text { Mother with mild } \\
\text { phenotype carries the } \\
\text { duplication }\end{array}$ & & $14.7-14.75$ & $16.3-16.77$ \\
\hline 13 (CHG00002373) & $\begin{array}{l}\text { Marked developmental delay, } 10=38 \text {, short stature }(150 \mathrm{~cm}) \text {, } \\
\text { microcephaly }(50,5 \mathrm{~cm}) \text {, neonatal seizures }\end{array}$ & $\begin{array}{l}\text { Phenotypically normal } \\
\text { mother carries deletion }\end{array}$ & Deletion & $16.3-16.77$ & $18.3-18.4$ \\
\hline
\end{tabular}

MR, mental retardation; OFC, occiptofrontal circumference.

In conclusion, we report a novel genomic disorder likely caused by NAHR between copies of LCR16. Although in some cases this is inherited from a normal parent, we found a strong association of the deletion with developmental disorders. Reciprocal duplications were observed as both inherited and de novo events, and were also identified in several controls, suggesting that the duplication by itself confers either no phenotype at all or a range of phenotypes of varying severity. Alternatively, the duplication may require additional predisposing factors to have a phenotypic effect. Our findings have important implications for genetic counselling. Traditionally, chromosomal imbalances inherited from a normal parent were considered benign, while de novo chromosomal imbalances were considered pathogenic. Although our results suggest that the inherited 16p13.11 deletion is likely causal for the phenotype, the clinical significance of both de novo and inherited duplications remains uncertain and they may be benign variants. The study of additional patients and normal individuals with $16 \mathrm{p} 13.11$ rearrangements is required to reinforce this hypothesis and to obtain better insight in the potential pathology associated with the observed microdeletion and microduplication events.

Author affiliations: ${ }^{1}$ Centre for Human Genetics, University Hospital, Catholic University of Leuven, Leuven, Belgium; ${ }^{2}$ Department of Genome Sciences, University of Washington School of Medicine, Seattle, Washington, USA;

${ }^{3}$ Department of Clinical Genetics, CHCG, Leiden University Medical Center, Leiden, The Netherlands; ${ }^{4}$ Department of Clinical Genetics, Oxford Radcliffe Hospitals NHS Trust, Churchill Hospital, Oxford, UK; ${ }^{5}$ Clinical and Molecular Genetics Unit, Institute of Child Health, University College London, London, UK and Department of Pediatrics, Academic Medical Center, University of Amsterdam, Amsterdam, The Netherlands; ${ }^{6}$ Oxford Partnership Comprehensive Biomedical Research Centre, Oxford Radcliffe Hospitals NHS Trust and The University of Oxford, The Wellcome Trust Centre for Human Genetics, Churchill Hospital, Oxford, UK; ${ }^{7}$ Department of Genome Sciences, University of Washington School of Medicine and the Howard Hughes Medical Institute, Seattle, Washington, USA

Acknowledgements: We are grateful to Dr R Krauss and the PARC project for the use and analysis of Illumina SNP genotyping data, the MicroArray Facility, Flanders Interuniversity Institute for Biotechnology (VIB) for their help in the spotting of the arrays and the Mapping Core and Map Finishing groups of the Wellcome Trust Sanger Institute for the initial clone supply and verification. We also thank Dr A Khan 
(Northamptonshire NHS Healthcare Trust, UK) and Dr A Barnicoat (Great Ormond Street Hospital for Children NHS Trust, UK) for their clinical contribution. This work was supported in part by grants from the NIH (HD043569, EEE), Merck Research Laboratories (AJS), Oxford Genetics Knowledge Park and the Oxford Partnership Comprehensive Biomedical Research Centre with funding from the Department of Health's NIHR Biomedical Research Centres funding scheme (the views expressed are those of the authors and not necessarily those of the Department of Health (RR and SJLK), the Catholic University of Leuven (GOA/2006/12 and Centre of Excellence SymBioSys, Research Council K.U.Leuven EF/05/007). EEE is an Investigator of the Howard Hughes Medical Institute.

Funding: This work was supported in part by grants from the NIH (HD043569, EEE), Merck Research Laboratories (AJS), Oxford Genetics Knowledge Park and the Oxford Partnership Comprehensive Biomedical Research Centre with funding from the Department of Health's NIHR Biomedical Research Centres funding scheme (the views expressed are those of the authors and not necessarily those of the Department of Health (RR and SJLK), the Catholic University of Leuven (GOA/2006/12 and Centre of Excellence SymBioSys, Research Council K.U.Leuven EF/05/007). EEE is an Investigator of the Howard Hughes Medical Institute.

Competing interests: None declared.

\section{REFERENCES}

1. Inoue K, Lupski JR. Molecular mechanisms for genomic disorders. Annu Rev Genomics Hum Genet 2002;3:199-242.

2. Bailey JA, Gu Z, Clark RA, Reinert K, Samonte RV, Schwartz S, Adams MD, Myers EW, Li PW, Eichler EE. Recent segmental duplications in the human genome. Science 2002;297:1003-7.

3. Sharp AJ, Hansen S, Selzer RR, Cheng Z, Regan R, Hurst JA, Stewart H, Price SM, Blair E, Hennekam RC, Fitzpatrick CA, Segraves R, Richmond TA, Guiver C, Albertson DG, Pinkel D, Eis PS, Schwartz S, Knight SJ, Eichler EE. Discovery of previously unidentified genomic disorders from the duplication architecture of the human genome. Nat Genet 2006;38:1038-42.

4. Balciuniene J, Feng N, lyadurai K, Hirsch B, Charnas L, Bill BR, Easterday MC, Staaf J, Oseth L, Czapansky-Beilman D, Avramopoulos D, Thomas GH, Borg A, Valle D, Schimmenti LA, Selleck SB. Recurrent 10q22-q23 deletions: a genomic disorder on $10 \mathrm{q}$ associated with cognitive and behavioral abnormalities. Am J Hum Genet 2007;80:938-47.

5. Loftus BJ, Kim UJ, Sneddon VP, Kalush F, Brandon R, Fuhrmann J, Mason T, Crosby ML, Barnstead M, Cronin L, Deslattes Mays A, Cao Y, Xu RX, Kang HL, Mitchell S, Eichler EE, Harris PC, Venter JC, Adams MD. Genome duplications and other features in $12 \mathrm{Mb}$ of DNA sequence from human chromosome 16p and 16q. Genomics 1999;60:295-308.

6. Martin J, Han C, Gordon LA, Terry A, Prabhakar S, She X, Xie G, Hellsten U, Chan YM, Altherr M, Couronne O, Aerts A, Bajorek E, Black S, Blumer H, Branscomb E, Brown NC, Bruno WJ, Buckingham JM, Callen DF, Campbell CS, Campbell ML, Campbell EW, Caoile C, Challacombe JF, Chasteen LA, Chertkov O, Chi HC, Christensen M, Clark LM, Cohn JD, Denys M, Detter JC, Dickson M, DimitrijevicBussod M, Escobar J, Fawcett JJ, Flowers D, Fotopulos D, Glavina T, Gomez M, Gonzales E, Goodstein D, Goodwin LA, Grady DL, Grigoriev I, Groza M, Hammon N, Hawkins T, Haydu L, Hildebrand CE, Huang W, Israni S, Jett J, Jewett PB, Kadner K, Kimball H, Kobayashi A, Krawczyk MC, Leyba T, Longmire JL, Lopez F, Lou Y, Lowry S, Ludeman T, Manohar CF, Mark GA, McMurray KL, Meincke LJ, Morgan J, Moyzis RK, Mundt MO, Munk AC, Nandkeshwar RD, Pitluck S, Pollard M, Predki P, ParsonQuintana B, Ramirez L, Rash S, Retterer J, Ricke D0, Robinson DL, Rodriguez A, Salamov A, Saunders EH, Scott D, Shough T, Stallings RL, Stalvey M, Sutherland RD, Tapia R, Tesmer JG, Thayer N, Thompson LS, Tice H, Torney DC, Tran-Gyamfi M, Tsai M, Ulanovsky LE, Ustaszewska A, Vo N, White PS, Williams AL, Wills PL, Wu JR, Wu K, Yang J, Dejong P, Bruce D, Doggett NA, Deaven L, Schmutz J, Grimwood J, Richardson P, Rokhsar DS, Eichler EE, Gilna P, Lucas SM, Myers RM, Rubin EM, Pennacchio LA. The sequence and analysis of duplication-rich human chromosome 16. Nature 2004;432:988-94.

7. Johnson ME, Cheng Z, Morrison VA, Scherer S, Ventura M, Gibbs RA, Green ED, Eichler EE. Recurrent duplication-driven transposition of DNA during hominoid evolution. Proc Natl Acad Sci U S A 2006:103:17626-31.

8. Ballif BC, Hornor SA, Jenkins E, Madan-Khetarpal S, Surti U, Jackson KE, Asamoah A, Brock PL, Gowans GC, Conway RL, Graham JM, Jr., Medne L, Zackai EH, Shaikh TH, Geoghegan J, Selzer RR, Eis PS, Bejjani BA, Shaffer LG. Discovery of a previously unrecognized microdeletion syndrome of 16p11.2-p12.2. Nat Genet 2007:39:1071-3.

9. Kriek M, Knijnenburg J, White SJ, Rosenberg C, den Dunnen JT, van Ommen GJ, Tanke HJ, Breuning MH, Szuhai K. Diagnosis of genetic abnormalities in developmentally delayed patients: a new strategy combining MLPA and array-CGH. Am J Med Genet A 2007;143:610-14.

10. Sharp AJ, Locke DP, McGrath SD, Cheng Z, Bailey JA, Vallente RU, Pertz LM, Clark RA, Schwartz S, Segraves R, Oseroff VV, Albertson DG, Pinkel D, Eichler EE. Segmental duplications and copy-number variation in the human genome. Am J Hum Genet 2005; 71:78-88.

11. Ullmann R, Turner G, Kirchhoff M, Chen W, Tonge B, Rosenberg C, Field M, ViannaMorgante AM, Christie L, Krepischi-Santos AC, Banna L, Brereton AV, Hill A, Bisgaard AM, Muller I, Hultschig C, Erdogan F, Wieczorek G, Ropers HH. Array CGH identifies reciprocal 16p13.1 duplications and deletions that predispose to autism and/or mental retardation. Hum Mutat 2007:28:674-82.
12. Mefford HC, Clauin S, Sharp AJ, Moller RS, Ullmann R, Kapur R, Pinkel D, Cooper GM, Ventura M, Ropers HH, Tommerup N, Eichler EE, Bellanne-Chantelot C. Recurrent reciprocal genomic rearrangements of $17 q 12$ are associated with renal disease, diabetes, and epilepsy. Am J Hum Genet 2007;81:1057-69.

13. Menten B, Maas N, Thienpont B, Buysse K, Vandesompele J, Melotte C, de Ravel T, Van Vooren S, Balikova I, Backx L, Janssens S, De Paepe A, De Moor B, Moreau Y, Marynen P, Fryns JP, Mortier G, Devriendt K, Speleman F, Vermeesch $J R$. Emerging patterns of cryptic chromosomal imbalance in patients with idiopathic mental retardation and multiple congenital anomalies: a new series of 140 patients and review of published reports. J Med Genet 2006;43:625-33.

14. Vermeesch JR, Melotte C, Froyen G, Van Vooren S, Dutta B, Maas N, Vermeulen S, Menten B, Speleman F, De Moor B, Van Hummelen P, Marynen P, Fryns JP, Devriendt K. Molecular karyotyping: array CGH quality criteria for constitutional genetic diagnosis. J Histochem Cytochem 2005;53:413-22.

15. Selzer RR, Richmond TA, Pofahl NJ, Green RD, Eis PS, Nair P, Brothman AR, Stallings RL. Analysis of chromosome breakpoints in neuroblastoma at sub-kilobase resolution using fine-tiling oligonucleotide array CGH. Genes Chromosomes Cancer 2005:44:305-19.

16. Li C, Wong WH. Model-based analysis of oligonucleotide arrays: expression index computation and outlier detection. Proc Natl Acad Sci U S A 2001;98:31-6.

17. Peiffer DA, Le JM, Steemers FJ, Chang W, Jenniges T, Garcia F, Haden K, Li J, Shaw CA, Belmont J, Cheung SW, Shen RM, Barker DL, Gunderson KL. Highresolution genomic profiling of chromosomal aberrations using Infinium wholegenome genotyping. Genome Res 2006;16:1136-48.

18. Johnson ME, Viggiano L, Bailey JA, Abdul-Rauf M, Goodwin G, Rocchi M, Eichler EE. Positive selection of a gene family during the emergence of humans and African apes. Nature 2001:413:514-19.

19. Redon R, Ishikawa S, Fitch KR, Feuk L, Perry GH, Andrews TD, Fiegler H, Shapero $\mathrm{MH}$, Carson AR, Chen W, Cho EK, Dallaire S, Freeman JL, Gonzalez JR, Gratacos M, Huang J, Kalaitzopoulos D, Komura D, MacDonald JR, Marshall CR, Mei R, Montgomery L, Nishimura K, Okamura K, Shen F, Somerville MJ, Tchinda J, Valsesia A, Woodwark C, Yang F, Zhang J, Zerjal T, Armengol L, Conrad DF, Estivill X, TylerSmith C, Carter NP, Aburatani H, Lee C, Jones KW, Scherer SW, Hurles ME. Global variation in copy number in the human genome. Nature 2006;444:444-54.

20. Iafrate AJ, Feuk L, Rivera MN, Listewnik ML, Donahoe PK, Qi Y, Scherer SW, Lee $\mathrm{C}$. Detection of large-scale variation in the human genome. Nat Genet 2004;36:949-51.

21. Sebat J, Lakshmi B, Troge J, Alexander J, Young J, Lundin P, Maner S, Massa H, Walker M, Chi M, Navin N, Lucito R, Healy J, Hicks J, Ye K, Reiner A, Gilliam TC, Trask B, Patterson N, Zetterberg A, Wigler M. Large-scale copy number polymorphism in the human genome. Science 2004;305:525-8.

22. Rosenberg C, Knijnenburg J, Bakker E, Vianna-Morgante AM, Sloos W, Otto PA, Kriek M, Hansson K, Krepischi-Santos AC, Fiegler H, Carter NP, Bijlsma EK, van Haeringen A, Szuhai K, Tanke HJ. Array-CGH detection of micro rearrangements in mentally retarded individuals: clinical significance of imbalances present both in affected children and normal parents. J Med Genet 2006;43:180-6.

23. Kirchhoff M, Gerdes T, Brunebjerg S, Bryndorf T. Investigation of patients with mental retardation and dysmorphic features using comparative genomic hybridization and subtelomeric multiplex ligation dependent probe amplification. Am J Med Genet $A$ 2005; 139:231-3.

24. Devriendt K, Swillen A, Fryns JP. Deletion in chromosome region 22q11 in a child with CHARGE association. Clin Genet 1998;53:408-10.

25. Krepischi-Santos AC, Vianna-Morgante AM, Jehee FS, Passos-Bueno MR, Knijnenburg J, Szuhai K, Sloos W, Mazzeu JF, Kok F, Cheroki C, Otto PA, Mingroni-Netto RC, Varela M, Koiffmann C, Kim CA, Bertola DR, Pearson PL, Rosenberg $\mathrm{C}$. Whole-genome array-CGH screening in undiagnosed syndromic patients: old syndromes revisited and new alterations. Cytogenet Genome Res 2006:115:254-61.

26. Ensenauer RE, Adeyinka A, Flynn HC, Michels VV, Lindor NM, Dawson DB, Thorland EC, Lorentz CP, Goldstein JL, McDonald MT, Smith WE, Simon-Fayard E, Alexander AA, Kulharya AS, Ketterling RP, Clark RD, Jalal SM. Microduplication 22q11.2, an emerging syndrome: clinical, cytogenetic, and molecular analysis of thirteen patients. Am J Hum Genet 2003; 73:1027-40.

27. de La Rochebrochard C, Joly-Helas G, Goldenberg A, Durand I, Laquerriere A, Ickowicz V, Saugier-Veber P, Eurin D, Moirot H, Diguet A, de Kergal F, Tiercin C, Mace $B$, Marpeau L, Frebourg T. The intrafamilial variability of the 22q11.2 microduplication encompasses a spectrum from minor cognitive deficits to severe congenital anomalies. Am J Med Genet A 2006;140:1608-13.

28. Yobb TM, Somerville MJ, Willatt L, Firth HV, Harrison K, MacKenzie J, Gallo N, Morrow BE, Shaffer LG, Babcock M, Chernos J, Bernier F, Sprysak K, Christiansen J, Haase S, Elyas B, Lilley M, Bamforth S, McDermid HE. Microduplication and triplication of 22q11.2: a highly variable syndrome. Am J Hum Genet 2005;76:865-76.

29. Lesnik Oberstein SA, Kriek M, White SJ, Kalf ME, Szuhai K, den Dunnen JT, Breuning $\mathrm{MH}$, Hennekam RC. Peters Plus syndrome is caused by mutations in B3GALTL, a putative glycosyltransferase. Am J Hum Genet 2006;79:562-6.

30. Yan X, Li F, Liang Y, Shen Y, Zhao X, Huang O, Zhu X. Human Nudel and NudE as regulators of cytoplasmic dynein in poleward protein transport along the mitotic spindle. Mol Cell Biol 2003;23:1239-50.

31. Feng $\mathbf{Y}$, Walsh CA. Mitotic spindle regulation by Nde1 controls cerebral cortical size. Neuron 2004; 44:279-93.

32. Kwon YT, Balogh SA, Davydov IV, Kashina AS, Yoon JK, Xie Y, Gaur A, Hyde L, Denenberg VH, Varshavsky A. Altered activity, social behavior, and spatial memory in 
mice lacking the NTAN1p amidase and the asparagine branch of the N-end rule pathway. Mol Cell Biol 2000;20:4135-48.

33. Amos-Landgraf JM, Ji Y, Gottlieb W, Depinet T, Wandstrat AE, Cassidy SB, Driscoll DJ, Rogan PK, Schwartz S, Nicholls RD. Chromosome breakage in the Prader-Willi and Angelman syndromes involves recombination between large, transcribed repeats at proximal and distal breakpoints. Am J Hum Genet 1999:65:370-86.
34. Shaw CJ, Withers MA, Lupski JR. Uncommon deletions of the Smith-Magenis syndrome region can be recurrent when alternate low-copy repeats act as homologous recombination substrates. Am J Hum Genet 2004;75:75-81.

35. Sharp AJ, Selzer RR, Veltman JA, Gimelli S, Gimelli G, Striano P, Coppola A, Regan R, Price SM, Knoers NV, Eis PS, Brunner HG, Hennekam RC, Knight SJ, de Vries BB, Zuffardi O, Eichler EE. Characterization of a recurrent $15 q 24$ microdeletion syndrome. Hum Mol Genet 2007:16:567-72.

\section{Drug and Therapeutics Bulletin (DTB)}

\section{Your key source of unbiased, independent advice}

For over 45 years DTB has been an independent, indispensable part of evidence-based clinical practice. DTB offers healthcare professionals detailed assessment of, and practical advice on, individual medicines and other treatments, groups of treatment and the overall management of disease.

DTB is now also available online at http://dtb.bmj.com:

- browse or search all DTB content from the latest issue back to 1994

- email alerting, sophisticated searching, RSS feeds and full text links from cited references

- interactive services such as My Folders for quick access to articles that you have viewed previously and My Searches to save and re-use useful searches

- comment online on any DTB article

To subscribe, or for further information, please visit http://dtb.bmj.com 